\title{
Los derechos fundamentales de las menores en las causales de despenalización del aborto (Juez de tutela y Corte Constitucional colombiana)
}

\author{
Comentario de Julia Sandra Bernal Crespo
}

Ciudad XX, treinta de mayo de dos mil once

\section{VISTOS Y OIDOS:}

PRIMERO: El once (11) de mayo de dos mil once (2011) la ciudadana Balder interpuso acción de tutela en representación de su hija menor de edad $\mathrm{AA}^{1}$, solicitando el amparo de sus derechos fundamentales a la dignidad humana, a la integridad personal, al libre desarrollo de su personalidad y a la salud, los cuales, en su opinión, están siendo amenazados por BB E.P.S, demandada al no responder de forma oportuna y no acceder a interrumpirle su embarazo a pesar de que está en peligro su salud física y mental, una de las hipótesis en las que la IVE (Interrupción Voluntaria del Embarazo) no es punible según la sentencia de la Corte Constitucional C-355 de 2006. Solicitó entonces que se ordene a BB E.P.S. que le practique la IVE a su hija.

SEGUNDO: Los hechos son los siguientes: El veintiocho (28) de marzo de 2011, AA de doce años de edad, acudió a la Institución Prestadora de Servicios de Salud (I.P.S), no vinculada con la E.P.S BB, para "confirmar embarazo y edad gestacional" y "solicitar información sobre la interrupción voluntaria del embarazo".

Tras una valoración, el médico DD expidió un certificado de riesgo para la salud como consecuencia de la continuación del embarazo. Concretamente señaló que estaba en riesgo su salud emocional ya que observó "frustración y depresión" y también su salud física por el peligro de "complicaciones obstétricas".

El nueve (9) de abril de 2011 AA acudió nuevamente a la I.P.S. -esta vez acompañada de su madre- y solicitó el servicio de interrupción voluntaria del embarazo por la causal de peligro para la salud, ante lo cual se le informó "qué hacer para solicitarlo en la EPS según sentencia C-355/06".

\footnotetext{
${ }^{1}$ En esta sentencia se desconoce el nombre del juez de tutela, la ciudad, el nombre de la menor, de su madre, de los médicos y de la entidad prestadora de salud (EPS), por orden expresa de la Corte Constitucional; todo lo anterior con el fin de proteger el derecho fundamental a la intimidad personal, de crear condiciones favorables para el acceso a la justicia, y de disminuir el número de mujeres que, a pesar de tener el derecho a la IVE, arriesgan su vida y su salud en sitios no autorizados.
} 
Los días doce (12) y veinticinco (25) de abril AA fue valorada por un médico psiquiatra y por una médico gineco-obstetra de la IPS, quienes certificaron que la continuidad del embarazo afectaba su salud mental y representaba un riesgo para su salud física. Estos certificados fueron adjuntados a la solicitud que por escrito presentó la madre de la menor el mismo día veinticinco (25) de abril a la EPS solicitando la IVE por razones de salud.

El día dos (2) de mayo la accionante se comunicó con la línea de atención al usuario de la E.P.S. BB para solicitar información acerca de la petición de IVE de su hija. Aseguró que le indicaron que "la petición había sido negada y que no le iban a realizar ningún procedimiento pues los certificados al ser expedidos por un médico fuera de la red no eran válidos y que dada la edad gestacional una terminación del embarazo ponía en riesgo la vida de su hija". A raíz de lo anterior, la actora acudió a un punto de servicio al cliente de la E.P.S. BB para solicitar una respuesta escrita. Indicó que adujeron que "no podían entregar respuesta porque dicho trámite se demoraba 15 días y aún estaban estudiando el caso".

El cinco (5) de mayo de 2011 la peticionaria radicó un escrito en la E.P.S. BB en la que se reforzaban los argumentos de la solicitud de IVE de su hija, en vista de que habían transcurrido ya nueve días desde la petición inicial sin respuesta escrita alguna.

TERCERO: el Juez de Tutela niega el amparo de los derechos fundamentales de la hija de la actora. Estimó que teniendo en cuenta el criterio de la $H$. Corte Constitucional en su sentencia C-355 de 2006 y las pruebas referenciadas, considera que no se dan las condiciones que supuestamente afectan y ponen en inminente riesgo y peligro la vida y salud de la menor, no se encuentran certificadas por un médico adscrito a la EPS en la que se encuentra vinculada la menor, tampoco está avalado el concepto emitido por el galeno de la entidad; y de igual manera según las pruebas aportadas, se advierte que la interrupción terapéutica del embarazo puede realizarse sin riesgo para la vida de la madre y el feto en las primeras 8 semanas de gestación y a la fecha la menor AA cuenta aproximadamente con 21 semanas de gestación, situación que sin duda pone en peligro la vida de la menor y del feto. El día 20 de septiembre de 2011 la menor da a luz.

Bogotá, D.C., tres (3) de noviembre de dos mil once (2011).

\section{VISTOS Y CONSIDERANDO:}

PRIMERO: Que la Corte Constitucional es competente para revisar la sentencia proferida dentro del proceso de la referencia, con fundamento en lo dispuesto por los artículos 86 y 241 numeral $9^{\circ}$ de la Constitución Política, en concordancia con los artículos 31 a 36 del decreto 2591 de 1991 y demás disposiciones pertinentes.

SEGUNDO: Que se revisará la sentencia del Juez de Tutela. Esta Sala de revisión debe determinar si la E.P.S BB vulneró el derecho fundamental a la IVE de la niña AA al no responder y no acceder a su petición de IVE a pesar de que, a juicio de la peticionaria, está incursa en una de las hipótesis en que ésta no es punible de conformidad con la sentencia C-355 de 2006 -peligro para la salud física o mental de la gestante-. 
En la mencionada sentencia C-355 de 2006, a raíz de una demanda de inconstitucionalidad contra varias normas del Código penal relativas al delito de aborto, la Corte decidió que su penalización absoluta era contraria a la Constitución. Esta consideración la llevó a indicar en la parte resolutiva de la sentencia que "no se incurre en delito de aborto, cuando con la voluntad de la mujer, la interrupción del embarazo se produzca en los siguientes casos:(i) Cuando la continuación del embarazo constituya peligro para la vida o la salud de la mujer, certificada por un médico; (ii) Cuando exista grave malformación del feto que haga inviable su vida, certificada por un médico; y (iii) Cuando el embarazo sea el resultado de una conducta, debidamente denunciada, constitutiva de acceso carnal o acto sexual sin consentimiento, abusivo o de inseminación artificial o transferencia de óvulo fecundado no consentidas, o de incesto".

Como se ha expresado en otras sentencias, resulta innegable que a partir de la sentencia C-355 de 2006 surgió en Colombia un verdadero derecho a la IVE en cabeza de las mujeres que se encuentran incursas en las hipótesis despenalizadas. Para la Corte la protección de los derechos fundamentales de la mujer a la dignidad humana, al libre desarrollo de la personalidad, a la vida y a la salud física y mental -contenidos en la Constitución de 1991 y en el bloque de constitucionalidad-imponen reconocerle la autonomía para decidir libremente si interrumpir o continuar la gestación al menos en las tres precisas circunstancias ya señaladas, de modo tal que la sanción penal resultaría desproporcionada. En otras palabras, del contenido mismo de los derechos fundamentales mencionados la Corte derivó una facultad, es decir, un derecho consistente en decidir si procrear o abstenerse de hacerlo, el cual se activa en cabeza de las mujeres gestantes cuando se encuentran en los eventos antes indicados.

TERCERO: El derecho fundamental a la IVE cuando existe peligro para la vida o la salud física o mental de la gestante, tuvo como fundamento el que resulta a todas luces un exceso requerir que la vida de la madre -ya formada- ceda ante el feto -apenas en formación-. En este orden de ideas, manifestó la Corporación: "si la sanción penal del aborto se funda en el presupuesto de la preeminencia del bien jurídico de la vida en gestación sobre otros bienes constitucionales en juego, en esta hipótesis concreta no hay ni siquiera equivalencia entre el derecho no sólo a la vida, sino también a la salud propia de la madre respecto de la salvaguarda del embrión”. Hizo hincapié la Corte en que la mujer en estado de gestación no puede ser obligada "a asumir sacrificios heroicos" ni puede conducirse "a ofrendar sus propios derechos en beneficio de terceros o del interés general". A su juicio, una obligación de esta entidad resulta por entero inexigible así el embarazo haya sido resultado de un acto consentido, máxime -agregó la Corporación- cuando se tiene en cuenta el artículo 49 superior que contiene el deber en cabeza de toda persona "de adoptar medidas para el cuidado de la propia salud".

También se indicó que la causal de peligro para la salud y la vida de la mujer gestante no cobija solamente la protección de su salud física sino que también se extiende a "aquellos casos en los cuales resulta afectada su salud mental", y evocó la disposición contenida en el artículo 12 de PIDESC según la cual la garantía del derecho a la salud supone gozar del "más alto nivel posible de salud física y mental". Concluyó la Corporación que el 
embarazo podría provocar "una situación de angustia severa o, incluso, graves alteraciones síquicas que justifiquen su interrupción según certificación médica".

CUARTO: Reitera la Sala en esta oportunidad que el derecho a la IVE, en aquellos casos en que no sea punible, tiene per se carácter fundamental ya que hace parte de los denominados derechos reproductivos y más exactamente de la autonomía reproductiva. Estos derechos incluyen el que la mujer tenga acceso a los servicios de salud para la IVE de forma segura, oportuna y con calidad, y por otra parte, la obligación de respeto y garantía en cabeza del Estado y de los prestadores y promotores del servicio de salud pública. En otras palabras, el Estado y los particulares que participan del Sistema General de Seguridad Social -E.P.S. e I.P.S- están en la obligación de abstenerse de imponer obstáculos ilegítimos, tales como exigir requisitos adicionales a los descritos en la sentencia C-355 de 2006, a la práctica de la IVE en las hipótesis despenalizadas.

En los casos de peligro para a vida y la salud integral de la mujer gestante la Corte precisó que el único requisito que se puede exigir para acceder a su petición de IVE es un certificado médico que dé cuenta de la amenaza. Específicamente en la hipótesis de afectación a la salud mental, en la sentencia T-388 de 2009 esta Sala subrayó que está terminantemente prohibido descalificar conceptos médicos expedidos por psicólogos pues la ley 1090 de 2006 les reconoce status de profesionales de la salud.

QUINTO: En este caso en concreto, aunque advierte la Sala que se presenta una carencia actual de objeto que determina que sea imposible llevar a cabo la IVE, pues AA dio a luz el veinte (20) de septiembre de 2011; lo único que procedería es el resarcimiento de los daños que hubieran podido originarse por la pretendida violación del derecho fundamental, lo cual es excepcionalmente permitido por medio de la acción de tutela.

De otro lado, la carencia actual de objeto por daño consumado no impide a esta Corte pronunciarse de fondo sobre la existencia de una violación de derechos fundamentales y la corrección de las decisiones judiciales de instancia. Ello es así porque este pronunciamiento tiene importantes efectos en materia de interpretación de los derechos fundamentales y prevención de sus futuras violaciones, además de que puede ser un primer paso para la reparación del daño ocasionado y la determinación de las responsabilidades administrativas, penales y disciplinarias.

SEXTO: De conformidad con lo expresado, procede la Sala a pronunciarse de fondo sobre el asunto de la referencia, al cabo del cual decidirá si hay lugar a tomar medidas en relación con la reparación del daño y las posibles responsabilidades que deriven de la violación de los derechos fundamentales.

Es necesario determinar entonces si BB E.P.S. violó el derecho fundamental de AA a la IVE. Encuentra la sala que la respuesta es afirmativa y que ello fue consecuencia de acciones y omisiones imputables a la demandada que revela el incumplimiento de las obligaciones de respeto y garantía del derecho fundamental mencionado 
La primera de estas omisiones fue la falta de respuesta oportuna a la solicitud de IVE presentada por AA. En efecto, AA presentó la petición a la E.P.S. demandada el veinticinco (25) de abril de 2011 y hasta el momento de la interposición de la presente acción de tutela -once (11) de mayo de dos mil once (2011)- habían transcurrido dieciséis días sin respuesta alguna. Según indica la misma E.P.S., en su escrito de contestación, sólo se disponía a iniciar las actividades encaminadas a responder la solicitud el veinticuatro (24) de mayo de 2011 -casi un mes después- fecha en el cual un médico adscrito a la E.P.S valoraría a la niña. El término de casi un mes que se tomó la E.P.S. para iniciar las acciones dirigidas a contestar la solicitud, de ningún modo es razonable tratándose de una IVE, ya que con cada mes de gestación se hace más riesgoso y complejo el procedimiento de interrupción.

La segunda de las conductas violatorias del derecho fundamental a la IVE de AA por parte de la E.P.S demandada fue exigirle un requisito adicional a los certificados médicos que fueron adjuntados a la petición. Si la demandaba estimaba que los certificados médicos debían ser refrendados por sus profesionales de la salud, ha debido proceder inmediatamente en vez de dilatar y negar el servicio de IVE.

Aclara la sala que la línea jurisprudencial sobre las prescripciones de los médicos externos, aplicada a la IVE, significa que la E.P.S debe proceder a refrendarla o refutarla científicamente a través de sus profesionales de la salud, pero tal trámite debe darse en todo caso dentro de los cinco días que constituyen el plazo razonable para contestar la solicitud de IVE.

SÉPTIMO: Es imperativo pronunciarse también sobre la decisión de instancia. En opinión de la Sala ninguno de los dos argumentos usados en ésta justificaba la negativa del amparo. Para la Sala, no es competencia del juez de instancia determinar la oportunidad para realizar la IVE, y en segundo lugar, ni en la sentencia C-355 de 2006 ni en ninguna norma legal se ha fijado un límite temporal para la realización de la IVE en los casos despenalizados, lo que no permite que el juez u otra autoridad o particular que participe en el sistema de salud, establezca una regla general que impida la IVE después de cierto tiempo de gestación, como lo sugirió el juez de instancia.

La Sala estima que la decisión sobre la realización de la IVE en una etapa de gestación cercana al nacimiento, debe ser tomada en cada caso concreto mediante una ponderación de (i) la causal de que se trate, (ii) de criterios médico ssoportados en la condición física y mental particular de la mujer gestante y, en todo caso, (iii) del deseo de la misma.

En mérito de lo expuesto, la Sala de revisión de la Corte Constitucional, administrando justicia en nombre del pueblo y por mandato de la Constitución

\section{RESUELVE}

PRIMERO.- REVOCAR el fallo proferido por el Juzgado PP que decidió negar el amparo de los derechos fundamentales de la actora, para en su lugar declarar la carencia actual de objeto por daño consumado en razón de la frustración del acceso a la interrupción voluntaria del embarazo, en la acción de tutela instaurada por Balder, en representación de su hija menor de edad AA, en contra de BB E.P.S. 
SEGUNDO.- CONDENAR en abstracto a BB E.P.S. a pagar el daño emergente y todos los demás perjuicios causados a AA por la negativa ilegítima de la interrupción voluntaria del embarazo, de conformidad con el artículo 25 del decreto 2591 de 1991. Los perjuicios deberán ser reparados en su integridad, para lo cual se deberá tener en cuenta, especialmente, la condición de menor de edad de AA y el daño ocasionado a su salud mental y a su proyecto de vida como consecuencia de la negación ilegítima del acceso a la IVE, a la cual tenía derecho.

La liquidación de los perjuicios se hará por el juez administrativo de QQ -reparto-, por el trámite incidental, el que deberá iniciarse dentro de los diez (10) días siguientes al recibo de la comunicación respectiva y deberá ser decidido en el término de los seis (6) meses siguientes, para lo cual la Secretaría General de esta Corporación remitirá inmediatamente copias de toda la actuación surtida en esta tutela a la Oficina Judicial respectiva.

TERCERO.- ORDENAR a BB E.P.S. que, dentro de las cuarenta y ocho (48) horas siguientes a la comunicación de la presente sentencia, como parte de la reparación ordenada en el numeral anterior, comience a prestarle a AA todos los servicios médicos que requiera a causa del nacimiento que se produjo, en lo que se refiere a su salud física pero especialmente en lo tocante con su salud mental. Al ser estos servicios parte de la reparación, no estarán limitados a los servicios incluidos en el POS sino a todos los necesarios de acuerdo con el criterio médico.

Así también la E.P.S. deberá prestar atención en salud al hijo de AA, mientras no pueda ser incluido en el régimen contributivo o subsidiado, para lo cual la peticionaria deberá adelantar las gestiones necesarias en caso de no haberlo hecho hasta el momento.

CUARTO.- ORDENAR al Instituto Colombiano de Bienestar Familiar, a la Secretaría de Salud de QQ y a la Secretaría de RR de QQ que, dentro de las cuarenta y ocho (48) horas siguientes a la comunicación de la presente sentencia, inicien los trámites para que, si AA lo desea, se le incluya en todos los programas dirigidos a madres adolescentes que estén disponibles y sean aplicables a su situación.

QUINTO.- COMPULSAR copias del expediente a la Superintendencia Nacional de Salud para que, dentro de las cuarenta y ocho horas (48) horas siguientes a la comunicación de la presente sentencia, en ejercicio de sus competencias, investigue y si es el caso sancione, las posibles faltas en que pudo incurrir en este caso BB E.P.S., lo que deberá incluir la corroboración de los hechos referidos en el párrafo 38 de la parte motiva de la sentencia.

SEXTO.- PREVENIR a BB E.P.S. para que en adelante responda oportunamente a las solicitudes de IVE y se abstenga de exigir requisitos adicionales a los fijados en la sentencia C-355 de 2006.

SÉPTIMO.- ORDENAR a la Superintendencia Nacional de Salud que, dentro de las cuarenta y ocho (48) horas siguientes a la comunicación de la presente sentencia, por 
los medios que considere efectivos y adecuados, inicie acciones tendientes a informar a las empresas promotoras de salud y las instituciones prestadoras de salud que:

(i) Deben responder de forma oportuna las solicitudes de IVE y en un término razonable, para ello y para realizar su práctica - de ser médicamente posible- es de cinco (5) días.

(ii) La E.P.S. a quien se le solicita la práctica de la IVE con base en una certificación médica de un profesional externo debe proceder, si lo considera necesario desde el punto de vista médico, a refrendarla o refutarla científicamente a través de sus profesionales de la salud, con base en la condición médica particular de la gestante, pero tal trámite debe darse en todo caso dentro de los cinco días que constituyen el plazo razonable para contestar la solicitud de IVE y proceder a la misma. De superarse este término se debe proceder a la IVE con base en el concepto del médico externo.

(iii) Ni la sentencia C-355 de 2006, ni ninguna norma legal ha fijado límite temporal alguno para la realización de la IVE en los casos despenalizados, por lo que no hay una regla general que impida la IVE después de cierto tiempo de gestación. Esta regla general tampoco puede ser establecida por los jueces ni por ninguna autoridad o particular que participe en el sistema de salud. Así, la decisión sobre la realización de la IVE en una etapa de gestación cercana al nacimiento debe ser tomada en cada caso concreto mediante una ponderación de la causal de que se trate, de criterios médicos soportados en la condición física y mental particular de la mujer gestante y, en todo caso, del deseo de la misma. Como toda intervención médica, la práctica de la IVE en estas condiciones debe estar precedida de un consentimiento idóneo e informado sobre el procedimiento a realizar y sus riesgos y beneficios.

OCTAVO.- ORDENAR a la Secretaría General de esta Corte y al juez de instancia limitar el acceso al expediente a las partes del presente proceso y guardar estricta reserva sobre la identidad de AA, so pena de las sanciones legales que correspondan por el desacato a esta orden judicial.

NOVENO.- ORDENAR a BB E.P.S., a la I.P.S. CC, a La Mesa por La Vida y la Salud de las Mujeres, a la Secretaría de Salud de QQ, a la Personería de QQ, a la Secretaría de RR de QQ, al Instituto Colombiano de Bienestar Familiar y a la Superintendencia Nacional de Salud guardar estricta reserva sobre la identidad de AA, so pena de las sanciones legales que correspondan por el desacato a esta orden judicial.

DÉCIMO.- ORDENAR al juez que le corresponda conocer del incidente de liquidación de perjuicios, ordenado en el numeral segundo de la presente sentencia, reservar en la sentencia la identidad de la titular del derecho y cualquier otro dato que conduzca a su identificación, así como restringir el acceso al expediente a las partes del proceso, a quienes debe ordenar guardar la misma reserva, so pena de las sanciones legales que correspondan por el desacato a la orden judicial. 
UNDÉCIMO.- ORDENAR a la Sala Administrativa del Consejo Superior de la Judicatura que, dentro de las cuarenta y ocho (48) horas siguientes a la comunicación de la presente sentencia, por los medios que estime más eficientes y adecuados, inicie actividades tendientes a informar a todos los jueces de la República lo siguiente:

(i) Todo juez que conozca de una tutela interpuesta para exigir el derecho fundamental a la IVE, en todo caso y con independencia del resultado del proceso, tiene la obligación de reservar en la sentencia la identidad del titular del derecho y cualquier otro dato que conduzca a su identificación, lo que incluye no solo su nombre sino, entre otros, su documento de identificación, lugar de residencia, números telefónicos, nombres de familiares, hijos, cónyuges o compañeros permanentes, instituciones de salud y personal médico que la atendió.

(ii) Esta reserva de identidad se deberá asegurar también a través de la limitación del acceso al expediente a las partes del proceso, quienes de todos modos deben guardar la misma reserva.

DÉCIMO SEGUNDO.- Por secretaría general, líbrense las comunicaciones previstas en el artículo 36 del decreto ley 2591 de 1991.

Notifíquese, comuníquese, publíquese en la Gaceta de la Corte Constitucional y cúmplase.

Referencia: expediente T-3. 130.813

Sentencia T-841 de 2011

Magistrado Ponente: Humberto Antonio Sierra Porto

\section{COMENTARio}

Esta sentencia de la Corte Constitucional, al igual que otros fallos de tutela en relación con el aborto despenalizado, reflejan el conflicto que aún existe en nuestra sociedad entre el derecho fundamental de las mujeres a su autonomía reproductiva, por un lado, y las creencias religiosas y los juicios morales, por el otro. Encontramos por ejemplo, que la Corte ordena reiteradamente en todos los fallos sobre aborto despenalizado ${ }^{2}$ que debe reservarse el nombre, identificación, residencia de la mujer, con el fin de proteger su privacidad e intimidad; para que se sienta libre de acceder a la justicia, y para evitar que sea objeto de reproches morales y religiosos por parte de la sociedad; aun cuando para la Corte es absolutamente claro que la decisión de una mujer de interrumpir voluntariamente su embarazo en las hipótesis expresadas, pertenece a la esfera íntima o privada, que la decisión la afecta solamente a ella y la sociedad no se ve perjudicada y, por tanto, no se trata de un asunto de interés público o general.

Este conflicto no solo lo encontramos a nivel de particulares sino también de personas que ejercen funciones públicas. En la sentencia T-388 de 2009, el juez de

${ }^{2}$ Por ejemplo, en las sentencias T-988 de 2007, T-946 de 2008, T-388 de 2009, T-209 de 2008, T-585 de 2010 . 
tutela había negado la solicitud de aborto por la presencia de un feto polimalformado con signos severos de displasia ósea, aduciendo la objeción de conciencia derivada del artículo 18 de la C.P. El juez estimó que la aplicación de esta figura se extendía también a las autoridades judiciales, por cuanto, en su opinión, tales autoridades eran también "seres humanos con formación sicológica, religiosa, cultural, etc.". La Corte determinó que las autoridades judiciales no pueden alegar objeción de conciencia, pues ellas dictan sus sentencias en derecho y no en conciencia.

En auto 327 de fecha 11 de octubre de 2010, la Sala Octava de la Corte Constitucional les recordó a las autoridades públicas la obligación de acatar las decisiones judiciales, máxime si estaban relacionadas con el imperio de las garantías constitucionales. En respuesta al informe que emitió el Procurador General de la Nación que "se refiere al respeto de los derechos fundamentales de las Instituciones que pueden verse involucradas en la práctica del procedimiento de interrupción del embarazo, y especialmente del derecho a la objeción de conciencia”, la Corte le responde que según jurisprudencia constitucional, en materia de interrupción del embarazo, sólo el personal médico y no las instituciones tienen derecho a la objeción de conciencia.

En relación con el punto de la autonomía reproductiva en mujeres menores de edad, para la Corte es claro que la facultad jurídica para solicitar la IVE en los casos en que se encuentra despenalizado la tienen todas las mujeres sin distinguir si son mayores o menores de edad. Sin embargo, me asalta la inquietud en relación con la norma penal que tipifica el delito de acceso carnal abusivo con menor de 14 años, pues según la Corte 3 el carácter abusivo de la conducta punible deriva de la circunstancia de ser realizado con persona que físicamente aún no ha llegado a la plenitud de su desarrollo corporal $\mathrm{y}$, especialmente, por tratarse de seres humanos que no han desarrollado su madurez volitiva y sexual, lo cual se presta para el aprovechamiento indebido de personas que lo aventajan. Pero, a renglón seguido, añade que es en el contexto social de la posibilidad de desarrollar la sexualidad que esta Corporación ha reconocido los derechos sexuales y reproductivos, para mostrar que las personas que tienen la capacidad de desarrollar su sexualidad cuentan con unos derechos que deben ser respetados y no pueden ser constreñidos o vulnerados, para hacer referencia a los menores entre 14 y 18 años.

${ }^{3}$ Sentencia C-876 de 2011. Comunicado de prensa fecha 22 de noviembre de 2011. 